\title{
La higiene mental en el México posrevolucionario: la psiquiatría en el siglo XX
}

\author{
Mental hygiene in post-revolutionary Mexico: \\ psychiatry in the twentieth century
}

\author{
José Antonio Maya González \\ Doctor en Historia, Facultad de Filosofía y Letras/Universidad Nacional Autónoma de México. \\ jomayago@gmail.com
}

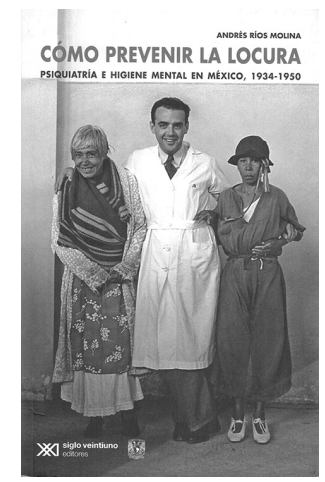

RÍOS MOLINA, Andrés. Cómo prevenir la locura: psiquiatría e higiene mental en México, 1934-1950. Ciudad de México: Instituto de Investigaciones Históricas/Universidad Nacional Autónoma de México; Siglo XXI. 2016. 232p. 【una serie de prácticas médicas en instituciones públicas y privadas, motivada por el desarrollo de la investigación, la instauración de una terapéutica farmacológica, la introducción de tecnologías para el diagnóstico, la consolidación de asociaciones y órganos de publicación presentes durante la primera mitad del siglo XX. Los nuevos profesionales en psiquiatría tenían la encomienda de salvaguardar el estado mental de la sociedad mediante la instauración de una serie de dispositivos de intervención y a través de la generación de instrumentos operativos cuya finalidad esencial era prevenir las enfermedades mentales de los mexicanos. Este proyecto de intervención-acción de la psiquiatría fue conocido bajo el nombre de higiene mental. El libro Cómo prevenir la locura: psiquiatría e higiene mental en México, 19341950, escrito por el historiador Andrés Ríos Molina, examina, por un lado, la profesionalización de la psiquiatría visto desde la esfera pública y, por el otro, estudia la génesis, auge y declive de la higiene mental en México. Se trata de una obra bien documentada y escrita con un lenguaje sencillo dirigida tanto al campo de los especialistas en historia de la psiquiatría como a los estudiosos en la salud pública

de México y América Latina, en la cual intercala con astucia la metodología de la historia intelectual, la historia de las ideas e instituciones.

Cómo prevenir la locura aporta información valiosa sobre la primera generación de psiquiatras impulsores de la higiene mental, las perspectivas ideológicas que sustentaron el movimiento, el diseño de políticas públicas, las diversas instituciones de atención que surgieron, sus alcances y limitaciones en el ámbito público así como las campañas de persuasión y control que se llevaron a cabo en la Ciudad de México en un lapso de poco más de 15 años. A partir de una exhaustiva lectura de documentos gubernamentales, administrativos, artículos 
médicos, boletines, informes, memorias de congresos, reglamentos, folletos, prensa nacional e internacional, y mediante un aparato teórico inspirado en los trabajos de Michel Foucault sobre el control social, Andrés Ríos Molina reconstruye el proceso de institucionalización de la higiene mental y analiza los mecanismos de intervención institucional encaminados a comprender, controlar y prevenir las enfermedades mentales en espacios diversos como escuelas, hospitales, talleres, fábricas y cárceles de la capital durante los gobiernos de Lázaro Cárdenas a Miguel Alemán.

La hipótesis central del libro es que la higiene mental fue un modelo de atención psiquiátrico basado en la detección, corrección y prevención de enfermedades mentales, el cual fue utilizado por el Estado mexicano como una "herramienta de control social" para vigilar a amplios sectores sumergidos en el fanatismo religioso, en el consumo de alcohol y enervantes, en la inmoralidad sexual, la falta de hábitos higiénicos y la propensión a la criminalidad. Los psiquiatras no sólo actuaban como garantes de los valores civilizatorios luego de una década de lucha armada, sino que fungían como "funcionarios del Estado" decididos a ejecutar acciones políticas en favor del bienestar físico y mental de los ciudadanos. Con un soporte ideológico interdisciplinario basado en la psicología introspectiva, la antropología y el psicoanálisis freudiano, los psiquiatras-higienistas entendían que las enfermedades mentales, lejos de cualquier consideración biologicista, eran producto de factores sociales y ambientales, razón por la cual una buena higiene mental implicaba ante todo, extirpar creencias religiosas y erradicar prácticas viciosas (sexualidades anormales, consumo de enervantes) que influían poderosamente en la psique del individuo y, a la vez, fomentar en los hogares, escuelas, fábricas y prisiones una estricta disciplina y amor al trabajo. Por lo tanto, la higiene mental tenía la finalidad de "reglamentar" ciertos aspectos de la vida cotidiana con el fin de combatir el mal rendimiento escolar, algunos problemas psicológicos derivados de las adicciones, la perversión moral y la criminalidad. La higiene mental en México surgió de la voluntad de los psiquiatras para mejorar las condiciones laborales, educativas y cívicas de grupos sociales en riesgo de padecer algún trastorno mental, por lo tanto, considerar la Higiene mental como un proyecto modernizador permite conjeturar que la socialización de la psiquiatría no sólo se logró a través de sus órganos rectores como el Instituto Nacional de Psicopedagogía (1936) y la Liga Mexicana de Higiene Mental (1938) sino también a través de una variedad de estrategias de persuasión (que incluía programas radiofónicos, folletos y películas) encaminadas, en todo caso, a fortalecer la imagen de un Estado preocupado por la salud de los ciudadanos.

Considero necesario resaltar un aspecto crucial en la historia de la higiene mental en México: al ser un movimiento gestado en el Manicomio General La Castañeda, fundado en 1910, bajo el empuje de la primera generación de psiquiatras y en el marco de la profesionalización de una disciplina vinculada a la investigación, docencia e intervención pública, posiblemente estamos ante la edad de oro de la psiquiatría mexicana. Dicha aseveración me surge por lo siguiente: en ningún otro momento los psiquiatras habían tenido tanto poder y respaldo estatal para gestionar, desarrollar e implementar políticas de salud pública como en el periodo de reconstrucción nacional, tomando en cuenta las problemáticas político-administrativas y el desamparo jurídico que experimentó el gremio desde la segunda mitad del siglo XIX hasta las primeras décadas del XX. Que los psiquiatras encabezaran un proyecto social basado en 
la prevención de las enfermedades mentales y surgiera una red de instituciones de atención alrededor de sus propuestas es una muestra elocuente de la legitimidad alcanzada por la flamante psiquiatría diplomada. Con la finalidad de sintetizar una obra por demás sugerente y provocadora, podemos caracterizar la higiene mental en México como un modelo de atención interdisciplinario (basado en saberes psicológicos, antropológicos y psicoanalíticos), interinstitucional (asociaciones, sociedades, ligas, instituciones, centros) y claramente vertical, debido a que se impuso como política de Estado bajo la impronta de un ciudadano idealizado sin considerar las particularidades sociales de la población citadina.

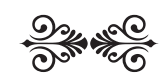

